\title{
Synthesis and characterization of mixture of nanozirconia and nanosilica obtained from commercially available zircon flour by sol-gel method
}

\author{
A J K PRASAD, S M SHASHIDHARA ${ }^{\dagger}$ and B K MURALIDHARA ${ }^{\dagger \dagger} * *$ \\ Department of Mechanical Engineering, Sir M. Visvesvarya Institute of Technology, Hunasmaranahalli, \\ Yelahanka, Bangalore 562 157, India \\ †Department of Mechanical Engineering, Siddaganga Institute of Technology, Tumkur 572 103, India \\ ${ }^{\dagger}$ Department of Mechanical Engineering, University Visvesvaraya College of Engineering, \\ Bangalore 560 001, India
}

MS received 3 April 2010

\begin{abstract}
In this paper we present the results of our patented (application filed in India) process for synthesizing a mixture of nanozirconia and nanosilica, obtained by the sol-gel method from commercially available zircon flour and hydrofluoric acid at low temperatures $\left(\sim \mathbf{1 0 0}^{\circ} \mathrm{C}\right)$. Within the scope of this study, 99.2\% dissolution of zircon was obtained by using $40 \% \mathrm{HF}$ for a solid-liquid (S/L) ratio of 0.05 for a digestion period of $120 \mathrm{~h}$. The nanoparticles, characterized by XRD, SEM and TEM techniques, were found to be largely spherical in shape and the average size of the particles was found to be less than $5 \mathrm{~nm}$. Within the product, zirconiarich and silica-rich regions were found to exist.
\end{abstract}

Keywords. Nanozirconia; nanosilica; zircon flour (commercially available); sol-gel method.

\section{Introduction}

Zircon is a refractory mineral and its decomposition is accomplished by very aggressive chemical attack, usually at high temperatures. The Gibbs free energy of formation of zircon from its oxides at $298 \mathrm{~K}, 10^{3} \mathrm{~Pa}$ has been reported to be $-19 \cdot 3 \pm 16 \mathrm{~kJ} / \mathrm{mol}$ (Newton and Manning 2005; Hugh and O'Neill 2006). $\mathrm{ZrO}_{2}-\mathrm{SiO}_{2}$ mixed oxides are promising candidate materials whose application spectrum includes high fracture toughness glass-ceramics (Nogami and Tomozawa 1986), high permittivity insulating films (Lucovsky and Rayner 2000; Gusev et al 2001; Lucovsky et al 2001; Stemmer et al 2003), catalytic process (Itoh et al 1974; Bosman et al 1994; Gomez et al 1994; Navio et al 1994; Miller and Ko 1996; Lopez et al 1999; Zhuang and Miller 2001) and a variety of optical coatings (Song et al 2002; He et al 2003; Li et al 2003).

The sol-gel method is used for the preparation of mixed oxides, such as $\mathrm{ZrO}_{2}-\mathrm{SiO}_{2}, \mathrm{ZrO}_{2}-\mathrm{Al}_{2} \mathrm{O}_{3}-\mathrm{SiO}_{2}$, etc because it is a low-cost process, requires inexpensive equipment having a distinctive advantage, in that, it can be scaled up to accommodate industrial scale production. Moreover, the sol-gel method offers high degree of compositional homogeneity content inherent with solution synthesis of multi-component inorganic materials. For

*Author for correspondence (prasad_ajk@yahoo.com) example, Nagarajan and Rao (1990) synthesized $\mathrm{ZrO}_{2}-$ $\mathrm{Al}_{2} \mathrm{O}_{3}-\mathrm{SiO}_{2}$ mixture by the sol-gel method. Researchers have synthesized nanozircon powders (Nogami 1984, 1985; Kadogawa and Yamate 1985; Vance 1986; Vilman 1987; Mirinda Salvado et al 1988; Kanno 1989; Nagarajan and Rao 1989; Mirinda Salvado and Navarro 1990; Kobayashi et al 1991; Hardy et al 1992; Mori and Yamamura 1992; Monros et al 1993; Taira et al 1993; Navio et al 1997; Tessy et al 2002) by the sol-gel method using pure chemical precursors, for example, zirconium oxychloride and sodium ethoxide (Kanno 1989), zirconium oxychloride and colloidal silica (Mori and Yamamura 1992), zirconium acetyl acetonate and tetraethylorthosilicate (TEOS) (Mirinda Salvado et al 1988), zirconium $n$-propoxide and TEOS (Mirinda Salvado and Navarro 1990), pure zirconium tetraisopropoxide (TPZR) and TEOS (Taira et al 1993), $\mathrm{ZrO}\left(\mathrm{NO}_{3}\right)_{2} \cdot 2 \mathrm{H}_{2} \mathrm{O}$ and colloidal silica (Vance 1986), $\mathrm{ZrOCl}_{2} \cdot 8 \mathrm{H}_{2} \mathrm{O}$ and TEOS (Vilman 1987), zirconyl nitrate and ethylsilicate (Nagarajan and Rao 1989) and zirconium acetate and colloidal silica (Monros et al 1993). Zircon powders (100\%) free from residual $\mathrm{ZrO}_{2}$ and $\mathrm{SiO}_{2}$ have been prepared by incorporating a transition metal ion as catalyst, TEOS and $\mathrm{ZrOCl}_{2}$. $8 \mathrm{H}_{2} \mathrm{O}-\mathrm{H}_{2} \mathrm{O}-\mathrm{Ni}\left(\mathrm{NO}_{3}\right)_{2} \cdot 6 \mathrm{H}_{2} \mathrm{O}-\mathrm{HCl}$ (Kadogawa and Yamate 1985).

We were interested in preparing a mixture of nanozirconia and nanosilica starting with commercially available zircon flour. The process involved digestion of 
commercially available zircon flour with concentrated hydrofluoric acid at low temperatures $\left(\sim 100^{\circ} \mathrm{C}\right)$ followed by treatment with isopropyl alcohol (IPA), neutralization with dilute ammonia and drying (Prasad et al 2006).

\section{Experimental}

Zircon flour, \#250-300 mesh (supplied by M/s Alcast Industries, Bangalore, India), was used in present investigations. Typical chemical analysis of the zircon flour used in the present contains zirconium dioxide $\left(\mathrm{ZrO}_{2}\right)$ $64.2 \mathrm{wt} \%$, silicon dioxide $\left(\mathrm{SiO}_{2}\right) 35.5 \mathrm{wt} \%$ and ferric oxide $\left(\mathrm{Fe}_{2} \mathrm{O}_{3}\right) 0.01 \mathrm{wt} \%$ and $\mathrm{Al}_{2} \mathrm{O}_{3}, 0.15 \mathrm{wt} \%$. Laboratorygrade reagents of $\mathrm{HCl}$ (Merk), ammonia solution (Merk), iso-propyl alcohol, 40\% HF (Merk), 60\% HF (local source), $30 \mathrm{wt} \% \mathrm{HF}$ were prepared by taking appropriate quantities of $60 \% \mathrm{HF}$ and distilled water.

Dissolution experiments were carried out in Teflon reactors ( $100 \mathrm{ml}$ capacity) encased in steel autoclaves by filling up 60-70\% volume with zircon flour and HF. Steel autoclaves were kept on electrically heated hot plates (maintained at $180-200^{\circ} \mathrm{C}$ ). Steel autoclaves were removed from the hot plate after the lapse of the required time, and after cooling, the contents of the Teflon reactors were filtered off. The digestion time and concentration of acid, in these experiments were 24, 48, 72, 96 and $120 \mathrm{~h}$ and 30, 40 and 60\%, respectively. Different solidliquid (S/L ratios, quantity of zircon flour and quantity of acid, w/v) studied were $0 \cdot 05,0 \cdot 1,0 \cdot 15$ and $0 \cdot 2$. Zircon dissolution (percentage) was determined by the weight of the residue after filtration, in each experiment. The dissolution experiments were repeated three times.

Equal volumes of the filtrate and isopropyl alcohol $(1: 1 \mathrm{v} / \mathrm{v})$ were taken in Teflon reactors (by filling 60$70 \%$ volume) encased in steel autoclaves. Steel autoclaves kept on electrically heated hot plates (maintained at $180-200^{\circ} \mathrm{C}$ ). Steel autoclaves were removed from the hot plate after $24 \mathrm{~h}$ and after cooling, the contents of the Teflon reactors were transferred to polypropylene beakers. The $\mathrm{pH}$ of the solution was adjusted to the near neutral range by neutralizing it with dilute ammonia solution to obtain a gel. The gel was repeatedly washed with distilled water till the fluoride ions were completely removed, as evidenced by the absence of formation of precipitate when few millilitres of the supernatant liquid treated with dilute silver nitrate solution. The gel was dried at ambient temperature with or without external circulation of air. In some experiments the gel was dried at $70^{\circ} \mathrm{C}$ for a period of $\sim 24 \mathrm{~h}$. The nanopowder was characterized by XRD, TEM and SEM techniques.

\section{Results and discussion}

The process flow sheet of the present investigation is given in figure 1. Dissolution of zircon as a function of time for 30, 40 and $60 \% \mathrm{HF}$ is presented in figure 2. For experiments carried out using $30 \% \mathrm{HF}$, a dissolution of $97.3 \%$ was obtained with an $\mathrm{S} / \mathrm{L}$ ratio of 0.05 , for a digestion time of $120 \mathrm{~h}$, and a dissolution of $94.1 \%$ for $24 \mathrm{~h}$ duration with an $\mathrm{S} / \mathrm{L}$ ratio of $0 \cdot 05$. For an $\mathrm{S} / \mathrm{L}$ ratio of $0 \cdot 2$, zircon dissolution was found to be 85.6 and $89.7 \%$ for the digestion periods of 24 and $120 \mathrm{~h}$, respectively.

Experiments carried out with 40 and $60 \%$ HF were yielding zircon dissolution above 94\%. Highest dissolution of $99.2 \%$ was observed while using $40 \% \mathrm{HF}$ for an $\mathrm{S} / \mathrm{L}$ ratio of 0.05 for a digestion duration of $120 \mathrm{~h}$.

In all the experiments, for a particular $\mathrm{S} / \mathrm{L}$ ratio, dissolution of zircon was found to increase with increase in digestion time and that for a particular digestion time, dissolution was found to decrease with increase in $\mathrm{S} / \mathrm{L}$ ratio. Furthermore, for a particular concentration of HF, maximum dissolution was found to take place for an $\mathrm{S} / \mathrm{L}$ ratio of $0 \cdot 05$, which peaked at $120 \mathrm{~h}$ of digestion time. Variation of dissolution as a function of time for $0.05 \mathrm{~S} / \mathrm{L}$ ratio is presented in figure 3 .

Interestingly, the highest dissolution of $99.2 \%$ was observed in the case of experiments carried out using $40 \% \mathrm{HF}$.

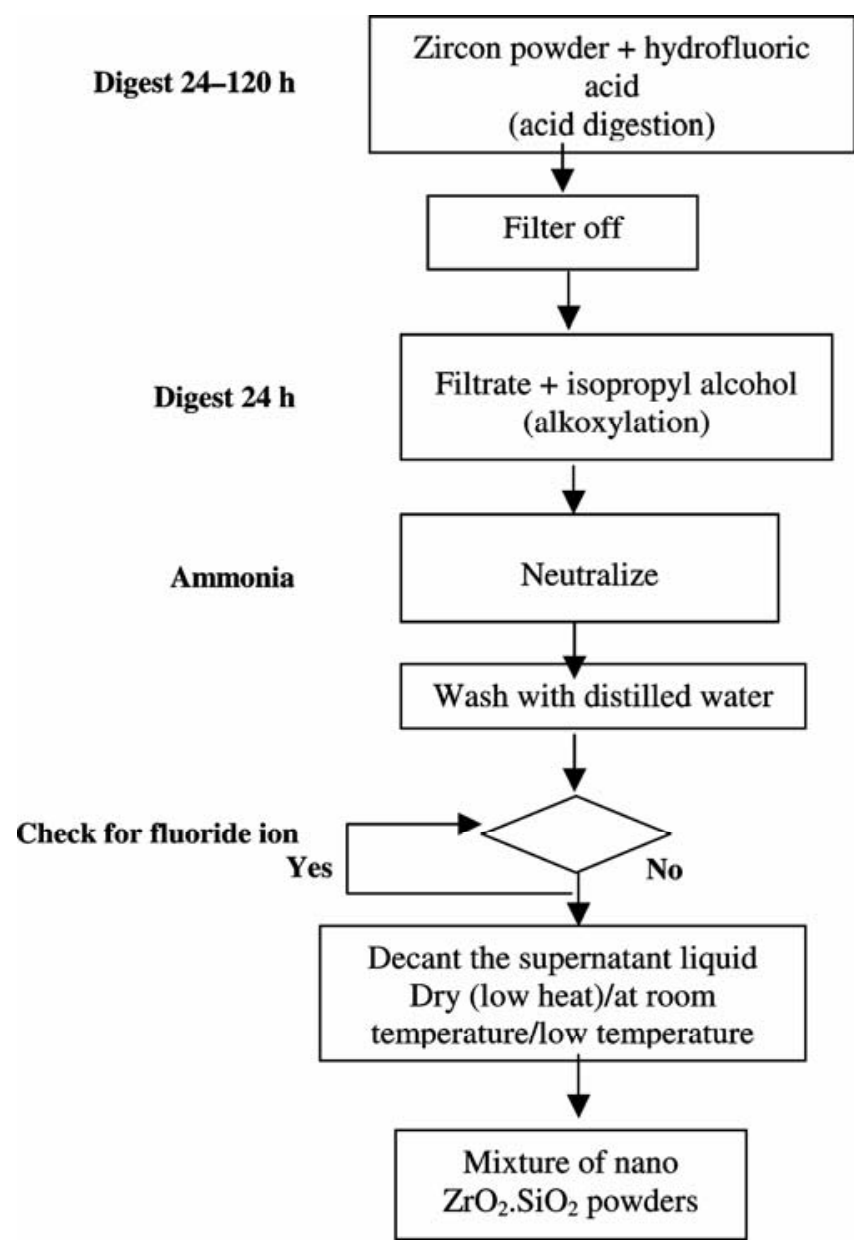

Figure 1. Process flow sheet for synthesizing mixture of nanozirconia and nanosilica (Prasad et al 2006). 

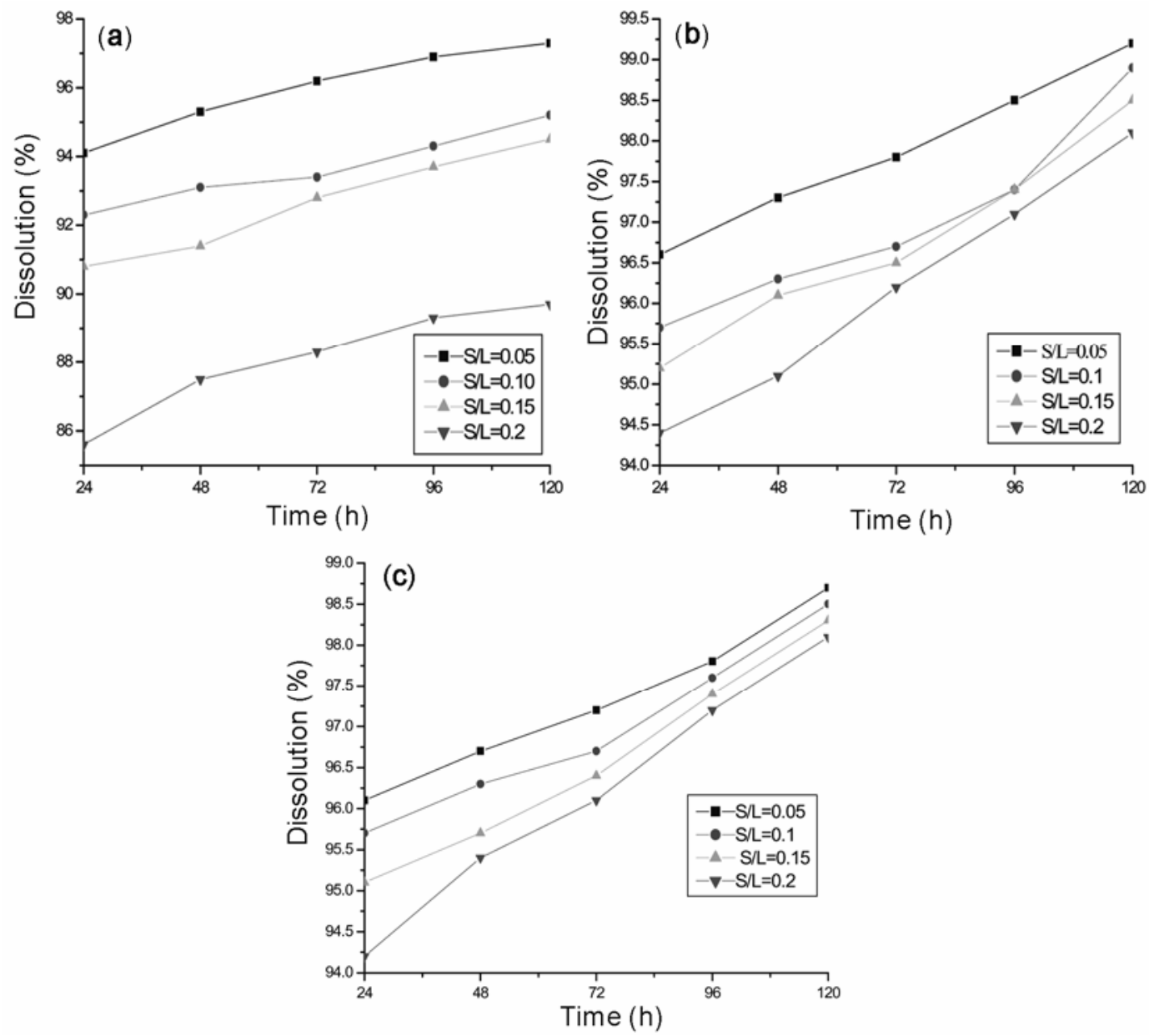

Figure 2. Dissolution of zircon in (a) $30 \% \mathrm{HF}$, (b) $40 \% \mathrm{HF}$ and (c) $60 \% \mathrm{HF}$.

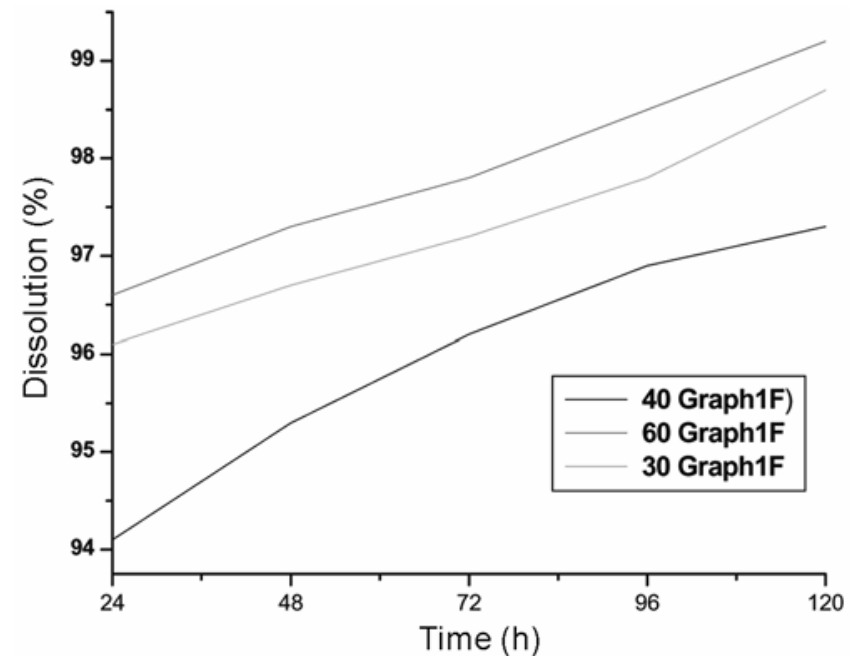

Figure 3. Variation of dissolution as a function of time for solid/liquid ratio.

However, with higher concentrations $(60 \% \mathrm{HF})$, we observed repeatedly dissolution of $97.8 \%$, which is less than the expected value.

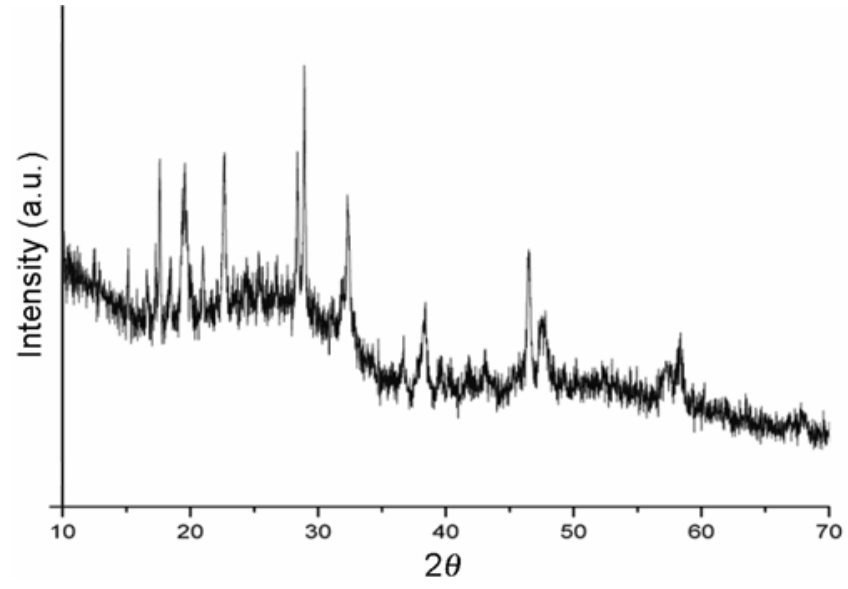

Figure 4. XRD pattern of mixture of nanozirconia and nanosilica.

After acid digestion, on opening the lid, we observed the formation of transparent needle-shaped crystals on the walls of the Teflon cup at the meniscus of the liquid. The length of these crystals has been found to be vary with time of digestion and concentration of HF used. The 

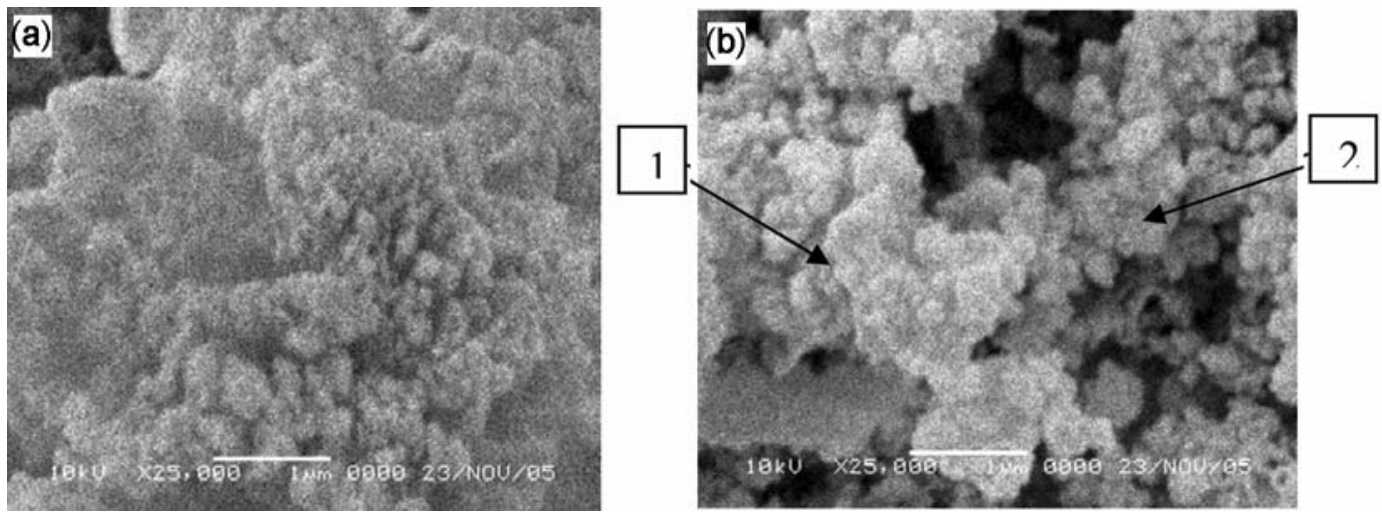

Figure 5. Scanning electron micrographs of a mixture of (a) nanozircon and (b) nanosilica taken at two different regions of a typical sample obtained by using $40 \% \mathrm{HF}$. (1) Zircon-rich region and (2) silica-rich region.
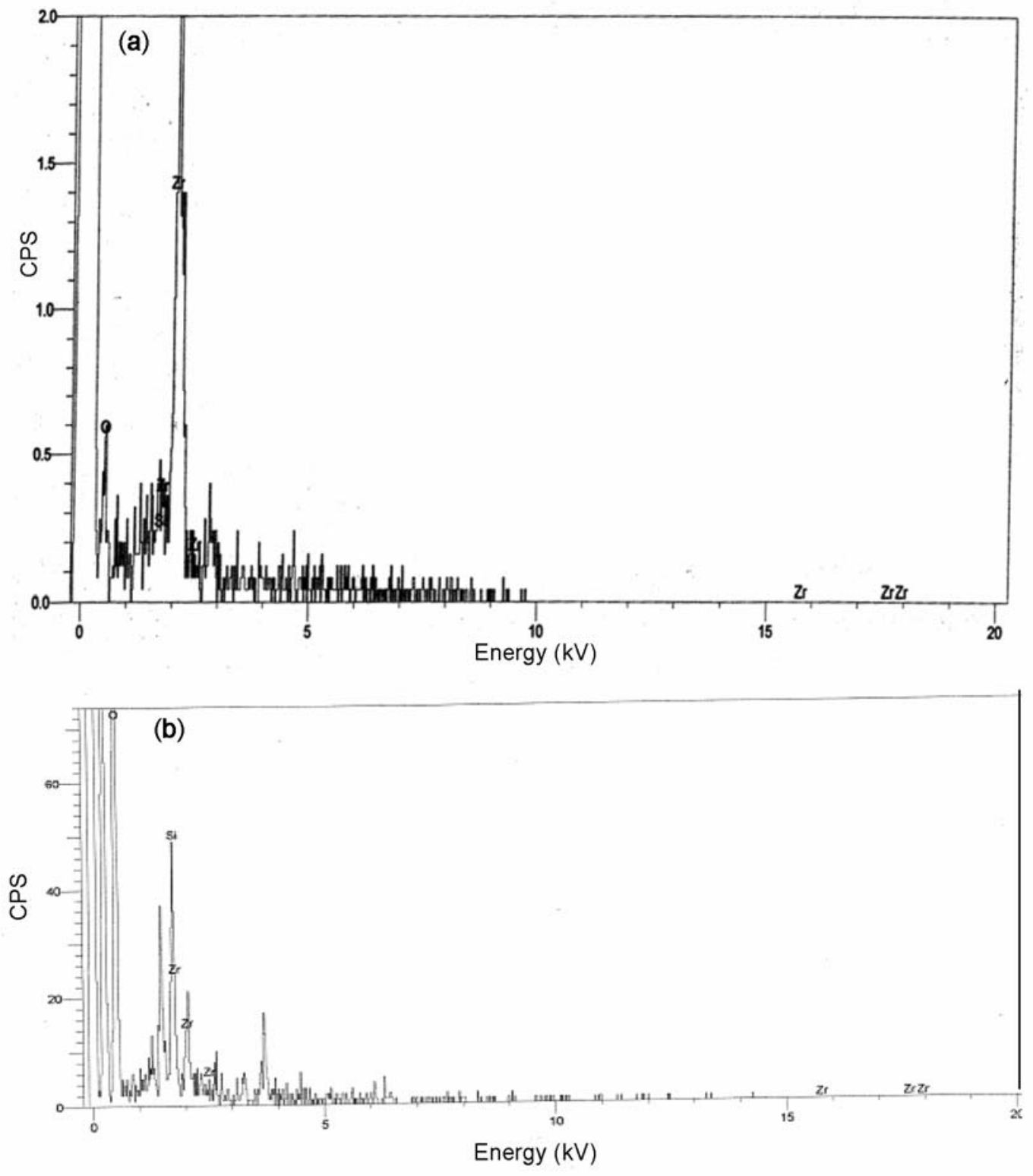

Figure 6. (a) EDX of zirconia-rich region of mixture of nanozircon and nanosilica (from region (1) in figure 5b). (b) EDX of silica-rich region of mixture of nanozircon and nanosilica (from region (2) in figure $5 b)$. 
population of these crystals was more in the case of experiments conducted using higher acid concentrations. These crystals dissolved upon vigorous stirring and are the possible reaction intermediates in the acid dissolution stage. It is well known from the literature (Craigen et al 1970) that zirconium tetrafluoride dissolves in dilute acids and can be recovered as monohydrate by crystallization from nitric acid solutions. Further, if the solution is acidified with hydrofluoric acid, $\mathrm{ZrF}_{4} \cdot 3 \mathrm{H}_{2} \mathrm{O}$ crystallizes at $10-30 \mathrm{wt} \% \mathrm{HF} ; \mathrm{HZrF}_{5} \cdot 4 \mathrm{H}_{2} \mathrm{O}$ crystallizes at $30-40 \mathrm{wt} \%$ $\mathrm{HF}$ and at higher concentrations, $\mathrm{H}_{2} \cdot \mathrm{ZrF}_{6} \cdot 2 \mathrm{H}_{2} \mathrm{O}$ can be produced. Hence, the addition of hydrofluoric acid to a concentrated solution of nitric acid solution of zirconium was observed to yield zirconium tetrafluoride precipitate.

Zirconium alkoxides are part of a family of alcoholderived compounds (Bradley 1978). The binary zirconium compounds have the general formula $\mathrm{ZRX}_{4-n}(\mathrm{OR})_{n}$. They are prepared by the reaction of zirconium tetrahalides and alcohols. The general reaction for the formation of zirconium alkoxides from halides proceeds as:

$$
\mathrm{ZrX}_{4}+3 \mathrm{ROH} \rightarrow \mathrm{ZrX}_{2}(\mathrm{OR})_{2} \cdot \mathrm{ROH}+2 \mathrm{HX} .
$$

During the second stage, alkoxylation of the respective fluorides takes place.

We envisage that the following reactions could be taking place during the various stages of the process investigated in the present studies (figure 1).

Formation fluoride(s) and fluoacid(s):

$$
\begin{aligned}
& \mathrm{ZrSiO}_{4}+8 \mathrm{HF} \text { (aq.) } \rightarrow \mathrm{ZrF}_{4}+\mathrm{SiF}_{4}+4 \mathrm{H}_{2} \mathrm{O}, \\
& \mathrm{ZrF}_{4}+\mathrm{SiF}_{4}+4 \mathrm{HF} \text { (aq.) } \rightarrow \mathrm{H}_{2} \mathrm{ZrF}_{6}+\mathrm{H}_{2} \mathrm{SiF}_{6} .
\end{aligned}
$$

Alkoxylation:

$$
\mathrm{ZrF}_{4}+\mathrm{SiF}_{4}+8 \mathrm{Pr}^{\mathrm{i}} \mathrm{OH} \rightarrow \mathrm{Zr}\left(\mathrm{OPr}^{\mathrm{i}}\right)_{4}+\mathrm{Si}\left(\mathrm{OPr}^{\mathrm{i}}\right)_{4}+8 \mathrm{HF},
$$

$$
\begin{aligned}
\mathrm{H}_{2} \mathrm{ZrF}_{6}+\mathrm{H}_{2} \mathrm{SiF}_{6}+8 \operatorname{Pr}^{\mathrm{i}} \mathrm{OH} \rightarrow \\
\mathrm{Zr}\left(\mathrm{OPr}^{\mathrm{i}}\right)_{4}+\mathrm{Si}\left(\mathrm{OPr}^{\mathrm{i}}\right)_{4}+12 \mathrm{HF} .
\end{aligned}
$$

Hydrolysis:

$$
\begin{aligned}
& \mathrm{Zr}\left(\mathrm{OPr}^{\mathrm{i}}\right)_{4}+\mathrm{Si}\left(\mathrm{OPr}^{\mathrm{i}}\right)_{4}+6 \mathrm{H}_{2} \mathrm{O} \rightarrow \\
& \mathrm{Zr}(\mathrm{OH})_{3} \cdot\left(\mathrm{OPr}^{\mathrm{i}}\right)+\mathrm{Si}(\mathrm{OH})_{3} \cdot\left(\mathrm{OPr}^{\mathrm{i}}\right)+6 \mathrm{Pr}^{\mathrm{i}} \mathrm{OH} .
\end{aligned}
$$

Polycondensation:

$$
\begin{aligned}
& \mathrm{Zr}-\mathrm{OH}+\mathrm{OH}-\mathrm{Zr}+\mathrm{Si}-\mathrm{OH}+\mathrm{OH}-\mathrm{Si} \rightarrow \\
& \quad \mathrm{Zr}-\mathrm{O}-\mathrm{Zr}+\mathrm{Si}-\mathrm{O}-\mathrm{Si}+2 \mathrm{H}_{2} \mathrm{O} .
\end{aligned}
$$

Dealcoholation:

$$
\begin{aligned}
& \mathrm{Zr}(\mathrm{OH})_{4}+\mathrm{Zr}\left(\mathrm{OPr}^{\mathrm{i}}\right)_{4} \rightarrow \mathrm{Zr}-\mathrm{O}-\mathrm{Zr}+4 \mathrm{Pr}^{\mathrm{i} O H}, \\
& \mathrm{Si}(\mathrm{OH})_{4}+\mathrm{Si}\left(\mathrm{OPr}^{\mathrm{i}}\right)_{4} \rightarrow \mathrm{Si}-\mathrm{O}-\mathrm{Si}+4 \mathrm{Pr}^{\mathrm{i}} \mathrm{OH} .
\end{aligned}
$$

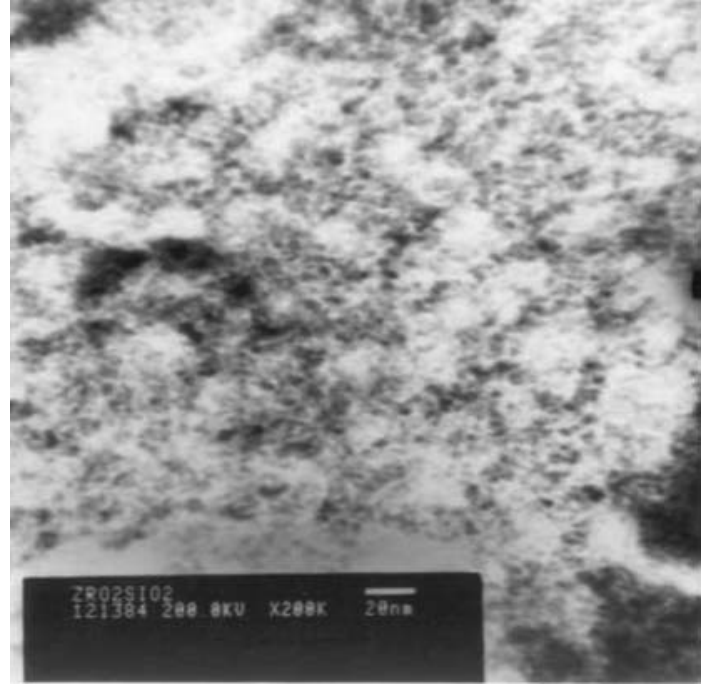

Figure 7. Transmission electron micrograph of mixture of nanozirconia and nanosilica.

The XRD pattern mixture of nano zirconia and nano silica (for a typical sample digested with $40 \% \mathrm{HF}, 120 \mathrm{~h}$ of dissolution with an S/L of 0.05) is shown in figure 4.

It is very clear that the absence of well-defined peaks in the XRD pattern (figure 4) indicates that the sample is indeed in the nanoform.

We present a typical scanning electron micrograph of the powder and the corresponding EDX pattern of the same sample taken at different locations in figures 5 and 6 , respectively.

From the figure 5 it is clear that the particles are spherical in shape and are highly agglomerated. It is also evident from figure 6 that, within the sample (a typical sample obtained by using $40 \% \mathrm{HF}, 0.05 \mathrm{~S} / \mathrm{L}$ and digested for $120 \mathrm{~h}$ ) zirconia-rich and silica-rich regions were observed. This phase separation could have taken place because of the different rates of hydrolysis of the respective alkoxides. Recently, it was reported in the literature (Gaudon et al 2005) that the existence of silica-rich and zirconia-rich regions in the sol-gel derived $\mathrm{ZrO}_{2}-$ $\mathrm{SiO}_{2}$ system, in the amorphous phase before crystallization.

Transmission electron micrographs of the mixture of nanozirconia and nanosilica are presented in figure 7 . It can be seen that the individual average particle size is $>5 \mathrm{~nm}$.

\section{Conclusions}

The results of the systematic investigations carried out indicate that within the scope of these investigations, it is possible to produce a mixture of nanozirconia and nanosilica powder from commercially available zircon flour and hydrofluoric acid by the sol-gel method. A maximum dissolution of $99.2 \%$ zircon was obtained by 
using $40 \% \mathrm{HF}$ for an $\mathrm{S} / \mathrm{L}$ ratio of 0.05 for a digestion period of $120 \mathrm{~h}$. The nanoparticles characterized by XRD, SEM and TEM techniques were found to be largely spherical in shape and the average size of the particles was found to be $>5 \mathrm{~nm}$. Within the product, zirconia-rich and silica-rich regions were found to exist. Further experiments are being carried out in the areas of developing strong and dense ceramics by powder metallurgy route and dental restorative polymer composites reinforced with this nanopowder.

\section{Acknowledgements}

We thank the managements of our institutions for the support and encouragement.

\section{References}

Bosman H J M et al 1994 J. Catal. 148660

Bradley D C 1978 Metal alkoxides (New York: Academic Press)

Craigen W J S et al 1970 Can. Metall. Q 9485

Gaudon A et al 2005 J. Eur. Ceram. Soc. 25283

Gomez R et al 1994 React. Kin. Catal. Lett. 53245

Gusev E P et al 2001 Microelectron. Eng. 59341

Hardy A B et al 1992 Preparation of zircon and mullite-zircon powders by sol-gel technique, in Chemical processing of advanced materials (eds) L L Hench and J K West (John Wiley and Sons) p. 577

He H et al 2003 Solid State Commun. 126639

Hugh St C and O'Neill 2006 Am. Mineral. 911134

Itoh M et al 1974 J. Catal. 35225
Kadogawa Y and Yamate 1985 Yogyo-Kyokai-Shi 93338

Kanno Y 1989 J. Mater. Sci. 242415

Kobayashi H et al 1991 J. Ceram. Soc. Jpn. 9942

Li Q et al 2003 Powder Technol. 13734

Lopez T et al 1999 J. Catal. 181285

Lucovsky G and Rayner G B 2000 Appl. Phys. Lett. 772912

Lucovsky G et al 2001 Microelectron. Rel. 41937

Miller J B and Ko E I 1995 J. Catal. 153194

Miller J B and Ko E I 1996 J. Catal. 15958

Mori T and Yamamura H 1992 J. Am. Ceram. Soc. 752420

Mirinda Salvado I M et al 1988 J. Non-Cryst. Solids 100330

Mirinda Salvado I M and Navarro F J M 1990 J. Mater. Sci. Lett. 9173

Monros G et al 1993 J. Mater. Sci. 285852

Nagarajan V S and Rao K J 1990 J. Solid State Chem. 88 419

Nagarajan V S and Rao K J 1989 J. Mater. Sci. 242140

Navio J A et al 1994 Appl. Surf. Sci. 81325

Navio J A et al 1997 J. Sol-Gel Sci. Tech. 10165

Newton R C and Manning CE 2005 J. Am. Ceram. Soc. 88 1854

Nogami M and Tomozawa M 1986 J. Am. Ceram. Soc. 6999

Nogami M 1985 J. Non-Cryst. Solids 69415

Nogami M 1984 J. Non-Cryst. Solids 178320

Prasad A J K et al 2006 A novel composition comprising of nanozirconina and nanosilica powder and a process for making the same official journal of the patent office in issue no. 44/2007, 2 November 2007, p. 27898

Song C et al 2002 Mater. Sci. Eng. B94 181

Stemmer S et al 2003 Jpn. J. Appl. Phys 423593

Taira M et al 1993 Dent. Mater. 9167

Tessy Lopez et al 2002 J. Sol-Gel Sci. Tech. 24207

Vilman G 1987 J. Mater. Sci. 223356

Vance E R 1986 Mater. Res. Bull. 21321

Zhuang Q and Miller J M 2001 Can. J. Chem. 791220 